\title{
1 Entomologia Experimentalis et Applicata
}

\section{Special Issue: Mark Jervis Memorial}

3

4 Sex ratios, virginity, and local resource enhancement in a

5 quasisocial parasitoid

6

7 Apostolos Kapranas ${ }^{1^{*}}$, Ian C.W. Hardy ${ }^{2}$, Xiuyun Tang ${ }^{3}$, Andy Gardner ${ }^{4} \&$ Baoping $\mathrm{Li}^{3}$ 8

$9{ }^{1}$ Institute of Biology, University of Neuchâtel, Emile-Argand 11, Neuchâtel 2000,

10 Switzerland, ${ }^{2}$ School of Biosciences, University of Nottingham, Sutton Bonington Campus,

11 Loughborough, LE12 5RD, UK, ${ }^{3}$ School of Plant Protection, Nanjing Agricultural

12 University, No. 1 Weigang, Nanjing, Jiangsu 210095, China, and ${ }^{4}$ School of Biology,

13 University of St Andrews, Sir Harold Mitchell Building, Greenside Place, St Andrews, KY16 $149 \mathrm{TH}, \mathrm{UK}$

*Correspondence: Apostolos Kapranas, FARCE Lab, Institute of Biology, University of Neuchâtel, Emile-Argand 11, Neuchâtel 2000, Switzerland

E-mail: akapranas@gmail.com, apostolos.kapranas@unine.ch

Running head: Sex ratios in a quasisocial parasitoid

Key words: Sclerodermus harmandi, Bethylidae, LRE, LMC, developmental mortality, allfemale broods, Hymenoptera

Accepted: 31 August 2015 


\section{Abstract}

2 Sclerodermus harmandi (Buysson) (Hymenoptera: Bethylidae) is an economically beneficial species of parasitoid wasp that has an unusual level of sociality: groups of female foundresses

4 reproduce on a single host and exhibit cooperative post-ovipositional brood care. The

5 beneficial effects females have on each other's reproductive success provide, via the theory

6 of local resource enhancement (LRE), an explanation for their female-biased progeny sex

7 ratios, which is part of the same framework for understanding sex-ratio evolution as the more

8 often invoked theory of local mate competition (LMC). Here we show that $S$. harmandi sex

9 ratios are over-dispersed, with high variance largely attributable to the common occurrence

$10(60 \%)$ of developmental mortality. Developmental mortality is also positively associated with

11 the proportion of broods which contain only females at emergence (virgin broods). Virginity

12 is more common when broods are produced by fewer foundresses. Virginity is expected to be

13 disadvantageous under LRE, as it is under LMC, but theory for LRE is less extensively

14 developed. We suggest approaches for the development of LRE theory, in particular using models of 'population elasticity' in which the intensity of kin competition is reduced because extra resources are available to local populations that are more cooperative. For S. harmandi,

17 such extra resources may include large hosts that can only be successfully utilized if multiple

18 foundresses cooperate. 


\section{Introduction}

2 Sex ratios in many species of gregarious and quasi-gregarious parasitoid wasps are female biased. In the vast majority of cases this can be explained by the theory of local mate competition (LMC) (Hamilton, 1967, 1979; Godfray, 1994; West, 2009). LMC theory predicts that female-biased sex ratios are selected for when the offspring produced by one or a few mothers, termed foundresses, mate among themselves before the female offspring disperse away from the natal group, a common feature of many parasitoid species (Hamilton 1967, 1979; Godfray, 1994; Hardy, 1994; Godfray \& Cook, 1997). LMC theory further predicts that bias will be less extreme when more foundresses contribute offspring to the mating group and such facultative adjustment of sex ratios is observed in empirical and comparative studies of parasitoids (Charnov, 1982; Godfray, 1994; Hardy, 2002; Hardy et al., 2005; West, 2009). In short, LMC theory has been a major key to the understanding of parasitoid sex allocation (Charnov 1982; Godfray, 1994; West, 2009; a critique of this success is provided by Orzack, 2002).

There are, however, some species of parasitoid wasps in which observed sex ratios are more biased than predicted by current LMC theory and/or do not vary with foundress numbers according to LMC predictions (Shuker et al., 2004, 2005; Matthews et al., 2009; Innocent et al., 2010; Abe et al., 2014; Tang et al., 2014). For instance, Abe et al. (2014) recently highlighted that the extremely female biased (1-5\% males), and relatively invariant sex ratios in the genus Melittobia (Hymenoptera: Eulophidae) are inexplicable using current sex-ratio theory. A concurrent publication by Tang et al. (2014) on parasitoids in the genus Sclerodermus (Hymenoptera: Bethylidae) similarly reported highly female-biased sex ratios, and although sex ratios increased significantly with foundress number, the effect was not strong. Like Abe et al. (2014), Tang et al. (2014) concluded that the observed sex ratios could not be explained by LMC but in contrast to Abe et al. (2014) it was concluded that current sex-ratio theory does provide an explanation: Sclerodermus harmandi (Buysson) is a quasisocial parasitoid (groups of females reproduce on a single host and exhibit cooperative brood care) and the beneficial effects females have on each other's reproductive success is expected to lead to female bias due to local resource enhancement (LRE), wherein an excess production of the sex that leads to a greater increase in fitness of the parents or their offspring is favoured (Taylor, 1981; West, 2009). This was the first report of LRE operating among parasitoid wasps and one of only a few reports on LRE within the Hymenoptera (Schwarz, 1988; Martins et al., 1999; Harradine et al., 2012). Although it is part of the same conceptual framework for understanding the evolution of sex allocation strategies, theory for LRE has 
not been as extensively developed as LMC theory (Taylor, 1981; West, 2009; Gardner \& Ross, 2013). In consequence, expectations for sex ratio means and variance and patterns of brood sexual composition in relation to other life-history variables such as foundress number, clutch size, or developmental mortality, are less well defined than under LMC (e.g., Green et al., 1982; Werren, 1983; Griffiths \& Godfray, 1988; Heimpel, 1994; Hardy et al., 1998).

In this companion paper to Tang et al. (2014), we summarize the pertinent biological details of S. harmandi and then, using the original data set of Tang et al. (2014), we further explore how its sex ratios are affected by foundress number and group size and also how developmental mortality and group size influence the incidence of virgin (all-female) broods. We go on to suggest how theory for LRE and quasisociality might be developed by consideration of the biology of Sclerodermus spp.

\section{Biology of Sclerodermus harmandi}

Sclerodermus harmandi is a gregarious ectoparasitoid of wood-boring cerambycid beetle larvae and is used extensively in biological control of coleopteran forest pests in China (Chen $\&$ Cheng, 2000). These beetles damage trees directly by feeding on them and also vector the extremely damaging pine wood nematode Bursaphelenchus xylophilus (Steiner \& Buhrer) Nickle which causes pine wilt disease (Yang et al., 2014).

In marked contrast to the aggressive behaviour observed when adult females in some other genera of the Bethylidae compete for exclusive access to a host (Hardy et al., 2013), Sclerodermus females appear to engage cooperatively in host suppression, oviposition, and offspring care (Bridwell, 1920; Wheeler, 1928; Kühne \& Becker, 1974; Mamaev, 1979; Casale, 1991; Hu et al., 2012; Wu et al., 2013), often producing very large broods of offspring (>100). Using S. harmandi, Tang et al. (2014) demonstrated experimentally that individual females increase their reproductive success by jointly exploiting large hosts, thus identifying the selective advantage of their quasisocial behaviour.

Some Sclerodermus species exhibit extremely female-biased sex ratios (Griffiths \& Godfray, 1988; Hardy \& Mayhew, 1998; Li \& Sun, 2011; Hu et al., 2012; Tang et al., 2014). Whereas most offspring groups consist mainly of females, some consist entirely of females ('virgin broods'). In $S$. harmandi, when males are present they are relatively short lived and typically mate with maturing brood-mate females when these emerge or prior to their emergence by chewing entrances into their cocoons (Zhang \& Tian, 1985; Hu et al., 2012).

\section{Materials and methods}


Sclerodermus harmandi was cultured at the Forestry Institute of Jiangsu Province, China, where it is mass-produced for release as an agent of biological control of Monochamus alternatus Hope (Coleoptera: Cerambycidae). Monochamus alternatus hosts were collected from forests in Liyang County (N 31.4 $4^{\circ}$ E $\left.119.4^{\circ}\right)$, China, during the winter of 2011, and maintained at $10{ }^{\circ} \mathrm{C}$ for $1-2$ months before use in experiments. The foundresses used in the experiment were collected from laboratory colonies where females had been mated with siblings upon emergence. In the treatments with more than one foundress, each foundress was obtained from a different parasitized host. Laboratory experiments were conducted at $25^{\circ} \mathrm{C}$ and $60-80 \%$ r.h.

The number of adult female $S$. harmandi introduced into a glass vial $(1.0 \mathrm{~cm}$ diameter, $5.0 \mathrm{~cm}$ long) with one $M$. alternatus larva was varied (1, 2, 4, 6, or 8$)$. The numbers of eggs laid onto each host, and the numbers of adult male and female $S$. harmandi offspring produced, were recorded. There were 220 replicates overall, with between 30 and 60 replicates for each number of foundress females. However, in about half of the replicates, foundresses failed to produce any offspring; this was especially common when foundress group sizes were small and/or hosts were large (Tang et al., 2014), and our current analysis is restricted to those replicates in which some S. harmandi offspring matured. Of the 112 replicates producing surviving offspring, one brood produced by a single foundress, consisted of eight males only, probably because the foundress had not mated. Another offspring group, produced by two foundresses, had an unusually large number of males (19/44 offspring), suggestive that one of the foundresses was unmated. Following procedures adopted by prior studies of bethylid sex ratios (e.g., Hardy \& Cook, 1995), these two replicates were excluded from the reported analyses. The inclusion of the two-foundress replicate would not have led to any different conclusion. There remained 110 offspring groups for analysis.

Data were mainly explored using logistic analysis (generalized linear modelling) in the GENSTAT statistical package (v. 14.1; VSN International, Hemel Hempstead, UK). All statistical testing was 2-tailed. Sex ratios were expressed as the proportion of adult offspring that were males. When binary data were grouped, we assumed quasi-binomially distributed errors to counter the effects of overdispersion (Wilson \& Hardy, 2002). Sex ratio variance and variance in mortality were each quantified using two descriptive statistics, the Heterogeneity Factor $(\mathrm{HF}=$ residual deviance/residual degrees of freedom; West \& Herre, 1998 ) and the variance ratio $\mathrm{R}$ (= variance in numbers observed/expected binomial variance; Nagelkerke \& Sabelis, 1998) and analysed using the Meelis test statistic U, which tests for departures from binomial distribution (significant large negative values indicate 
underdispersion and large positive values overdispersion; Nagelkerke \& Sabelis, 1998; Krackow et al., 2002). Values of $R$ and $U$ are calculated from sums of separate calculations from each offspring group size and we note that our data consist of small numbers of clutches or broods spread across a large range of group sizes. Although the approach we adopt is the best currently available, it is known that when data consist of many small sub-samples estimations can be distorted such that, for instance, larger values might not correspond to stronger deviations from expected variances (Krackow et al., 2002).

\section{Results}

Among the 110 broods in which some offspring matured, overall $61 \%$ offspring had died during development (mean \pm SE egg-to-adult mortality $=0.614 \pm 0.021$ ), and mortality had variance that was not significantly greater than binomial $(H F=28.3$; Meelis test: $R=12.61$, $\mathrm{U}=85.43, \mathrm{P}=1.0$ ). It is already known that developmental mortality is unrelated to host weight, the number of eggs laid on a host, or the number of foundress females present (Tang et al., 2014). Unsurprisingly, the size of the offspring group at maturity was negatively correlated with egg-to-adult mortality (Spearman's rank correlation: $r=-0.757, t=12.12$, d.f. $=109, \mathrm{P}<0.001)$. The sex ratios of groups of maturing adults were typically strongly female biased (mean proportion of offspring that were male $=0.069 \pm 0.004-$ note that an incorrect mean value of 0.032 was reported by Tang et al., 2014). Sex ratio variances were overdispersed $(\mathrm{HF}=1.48$; Meelis test: $\mathrm{R}=0.7208, \mathrm{U}=2.33, \mathrm{P}=0.020)$.

Sex ratios decreased weakly with adult offspring group size (Logistic ANCOVA corrected for overdispersion: $\mathrm{F}_{1,109}=5.55, \mathrm{P}=0.02, \%$ deviance explained $=4.75$; Figure 1 ) and increased weakly with foundresses number $\left(\mathrm{F}_{4,109}=5.63, \mathrm{P}<0.001, \% \mathrm{dev}=4.81\right.$; Figure 1). There was no significant interaction between these two main effects $\left(\mathrm{F}_{4,109}=1.08, \mathrm{P}=\right.$ $0.37)$. The number of males present in offspring group increased with group size $\left(\mathrm{F}_{1,108}=\right.$ 80.97, $\mathrm{P}<0.001, \% \operatorname{dev}=42.8$ ). Sex ratio variance, quantified by HF, was not correlated with the number of foundresses producing the brood (one: $\mathrm{HF}=1.64, \mathrm{n}=9$; two: $\mathrm{HF}=0.816, \mathrm{n}=$ 20; four: $\mathrm{HF}=1.24, \mathrm{n}=31$; six: $\mathrm{HF}=0.595, \mathrm{n}=21$; eight: $\mathrm{HF}=2.25, \mathrm{n}=28$; Spearman's rank correlation: $\mathrm{r}=0.100, \mathrm{P}=0.20$ ). Sex ratios were significantly higher among broods that had experienced higher proportions of developmental mortality $\left(F_{1,108}=10.21, P=0.002, \%\right.$ $\operatorname{dev}=8.63$; Figure 2). Sex ratio variance was significantly higher among broods that experienced the highest percentages of developmental mortality $(\leq 24.9 \%$ mortality: $\mathrm{HF}=$ $0.46, \mathrm{n}=9 ; 25-49.9 \%: \mathrm{HF}=0.953, \mathrm{n}=27 ; 50-74.9 \%$ : $\mathrm{HF}=2.08, \mathrm{n}=42 ; \geq 75 \%: \mathrm{HF}=1.13$, $\mathrm{n}=32$; Spearman's rank correlation: $\mathrm{r}=0.800, \mathrm{P}=0.021$ ). 
About $15.3 \%$ of adult offspring groups consisted of female offspring only. The probability of an offspring group consisting only of females was lower among larger offspring groups $\left(\mathrm{G}_{1}=32.39, \mathrm{P}<0.001, \% \mathrm{dev}=34.0\right)$; no broods of more than around 50 maturing offspring contained females only (Figure 3). The probability of all-female offspring groups was higher when developmental mortality was higher $\left(\mathrm{G}_{1}=20.68, \mathrm{P}<0.001, \% \mathrm{dev}=\right.$ 21.7) and when foundresses number was lower $\left(\mathrm{G}_{4}=5.26, \mathrm{P}<0.001, \% \mathrm{dev}=22.1\right.$; Figure 4). The interaction between these two variables was not significant $\left(\mathrm{G}_{4}=0.19, \mathrm{P}=0.95\right)$.

\section{Discussion}

The highly female-biased sex ratios observed in S. harmandi appear to be due to LRE (the mutually beneficial foundress-foundress interactions contribute to the value of female offspring; Taylor, 1981) rather than to the more usual explanation of LMC (Hamilton, 1967). We first consider the brood compositions observed in $S$. harmandi in regard to current literature and then suggest an approach for how models can be developed to better evaluate the assertion that $S$. harmandi sex ratios have principally evolved due to LRE.

Current evidence suggests that Sclerodermus foundresses tend to each lay a small number of male eggs in every clutch (Mamaev, 1979; Liu et al., 2011; Tang et al., 2014). Mamaev (1979) reported that 1-2 males are laid among the first produced eggs in each clutch (a pattern which may be associated with final clutch size uncertainty; Hardy, 1992). Similarly, Tang et al. (2014) estimated that on average 0.8 adult males are produced per $S$. harmandi foundress, suggesting that (given $61 \%$ developmental mortality) each foundress lays an average of 1.31 male eggs in each clutch. Further, the brood sex ratios produced by single foundresses are typically less female biased than the reciprocal of brood size (one male per brood is expected under single-foundress LMC in the absence of developmental mortality; Green et al., 1982; Griffiths \& Godfray, 1988; Nagelkerke \& Hardy, 1994), due to mothers laying more males in larger broods than in smaller broods. Weak declines in sex ratio with increasing brood size, as observed in $S$. harmandi, or a lack of relationship between sex ratio and brood size, have been reported for the secondary sex ratios (at adult emergence) of most examined sub-social bethylids in which broods are produced by a single foundress and, as observed for $S$. harmandi, are typically associated with an increase in the number of males per brood as brood size increases (Hardy et al., 1998). However, examination of the primary sex ratio (at oviposition) in one sub-social species has shown that developmental mortality may alter or obscure initially present relationships (Khidr et al., 2013). Given that developmental mortality among $S$. harmandi offspring is more common than is observed in 
many gregarious parasitoids (Hardy et al., 1998; Kapranas et al., 2011), empirical assessment of the primary sex ratio is a desirable future step, especially as such evaluation could potentially also reveal the relative contributions of individual foundresses to each offspring group (Khidr et al., 2014) and thus provide insights into whether the apparently cooperative reproduction observed is in fact tempered by reproductive dominance and skew (Tang et al., 1994).

Sex ratio variances were overdispersed, most likely due to the scrambling effect developmental mortality has on initially less variable group sexual compositions, as observed within and across other species of gregarious parasitoids (Hardy et al., 1998; Kapranas et al., 2011; Khidr et al., 2013). Theory for sex ratio variance under LRE is not well developed; but under LMC, selection for low sex ratio variance can be less stringent in multiple-foundress cases compared to single-foundress cases (Nagelkerke, 1996); our rather limited data do not suggest a relationship between variance and foundress number. Further, selection for sex ratio variance is expected to be related to the frequency at which different numbers of foundresses naturally occur (West \& Herre, 1998) but there is very little field data on the distribution of foundress numbers in $S$. harmandi populations. The less female-biased sex ratios in broods which experienced higher proportions of mortality is suggestive of higher mortality among developing females than among males, which may be attributable to female larvae requiring more resources than male larvae to grow large enough for successful pupation (Nagelkerke $\&$ Hardy, 1994), and indeed S. harmandi females are larger than males (He, 2004), and could also result from sexually differential care by brood-tending foundresses.

Whereas the current evidence suggests that developmental mortality increases brood sex ratio variance in $S$. harmandi, there is much stronger evidence for an association between mortality and a related aspect of brood sexual composition: all-female ('virgin') broods, which can result from all males in a brood dying before maturity. Under single-foundress LMC, hymenopteran parasitoids maturing in all-female broods are expected to have low fitness due to being constrained to subsequently produce male-offspring only, and these will have no reproductive opportunities unless some inter-group dispersal and non-local mating occurs (Green et al., 1982; Godfray, 1990; Heimpel, 1994; Nagelkerke \& Hardy, 1994; Hardy et al., 1998, 2005). Virgin females co-founding broods with mated females can obtain fitness via their sons mating locally with the offspring of the co-foundresses, but are not able to produce offspring sex ratios close to the unconstrained optima and are thus also disadvantaged (Godfray, 1990; West, 2009). Despite the disadvantage of virginity, virgin broods are predicted to arise under LMC due to the trade-off between minimising the number 
of male offspring produced and insuring against all the males dying before maturity (Green et al., 1982; Heimpel, 1994; Nagelkerke \& Hardy, 1994; West et al., 1997). In general accord with these expectations from LMC theory, virgin S. harmandi broods were more common when brood sizes were smaller, when mortality was more prevalent, and also when broods were produced by fewer foundresses. Similar patterns have been observed in gregarious parasitoids with LMC (Hardy et al., 1998; Kapranas et al., 2009, 2011) and across fig wasp species with LMC (West et al., 1997). Further, the relationships between the prevalence of virginity and the prevalence of mortality for $S$. harmandi broods produced by one or two foundresses resemble explicit predictions for the one- and two-foundress cases under LMC (Figure 1d in West et al., 1997). Whether these apparent matches to the predictions of 'extended' LMC theory (West, 2009) counter the assertion (Tang et al., 2014) that 'classical' LMC does not explain sex ratios in $S$. harmandi is currently unclear and may require the development of equivalent theory for virginity under LRE.

In mixed sex broods, with female-biased sex ratios, current evidence suggests that local (within brood) mating is the norm. Given a mean sex ratio of 0.069 , individual males will typically mate with around 14 females and evidence from other bethylids suggests that they will have sufficient supplies of sperm with which to successfully inseminate all the females (Hardy et al., 2005), although at high-mating frequencies males are expected (Abe \& Kamimura, 2015) and observed (e.g., in the bethylid Goniozus legneri Gordh; Gordh et al., 1983) to transfer smaller ejaculates. The occurrence of virgin broods suggests that non-local mating, via male dispersal, may also occur, due to the selection pressure on males to acquire more mates (e.g., by immigrating into virgin broods) and that females may be receptive due to the selective advantage for being able to produce female-biased offspring sex ratios. Male S. harmandi typically possess wings which is suggestive of male dispersal but there is a lack of direct evidence for the mating structure of Sclerodermus populations (as with other bethylids; Hardy \& Cook, 1995; Hardy \& Mayhew, 1998; Hardy et al., 2000).

After maturing around the remains of a host, female Sclerodermus must disperse to forage for a fresh host. Females typically do not possess wings and so forage by walking. It is not currently known whether females disperse as individuals or as cohesive groups, although reports that females overwinter in groups in host-made tunnels or cavities in trees (Zhang \& Tian, 1985; Xu et al., 2002) do suggest group cohesion. The direct selective advantage to cohesive dispersal and foraging would be that it would promote successful reproduction on large hosts (Tang et al., 2014). Cohesive dispersal would also enhance the relatedness between foundresses, which may in turn select for more strongly biased sex ratios (and other 
aspects of social behaviour) compared to situations when foundresses were not closely related (Taylor \& Crespi, 1994; Shuker et al., 2004; Gardner et al., 2009; Abe \& Kamimura, 2012). We, however, speculate that females maturing in virgin broods may not disperse as cohesively as females from mixed-sex broods, due to the expected mating opportunities to a virgin foundress's sons being greater when her co-foundresses are not also virgins.

In summary, many patterns in the sexual composition of $S$. harmandi broods are similar to those observed in other gregarious, but sub-social, bethylids and also in some socially solitary species. Sex ratios in these other species are typically interpreted in the context of LMC theory whereas, on current evidence, S. harmandi sex ratios are better explained by LRE. This does not preclude that LMC effects are also operating and indeed they are expected given that within-brood mating occurs. While LMC and LRE are part of the same theoretical framework (Taylor, 1981), models for sex allocation under LRE are less extensively developed than are LMC models (West, 2009). We now turn to considering how best to develop LRE theory to probe the current explanation for sex ratio bias in Sclerodermus.

We have suggested that mutually-beneficial cooperative interaction between foundresses select for female-biased sex allocation through LRE to the extent that a female's daughters tend to reproduce in close proximity of each other. However, whilst such a 'viscous' population structure can ensure high relatedness between social partners, it can also lead to intense competition between kin for limiting reproductive resources (Hamilton, 1964), and this kin competition effect can inhibit or even override the effects of increased relatedness on sex allocation and other social evolutionary traits (Bulmer, 1986; Frank, 1986; Taylor, 1988, 1992a; Gardner et al., 2009; Rodrigues \& Gardner, 2015). Accordingly, a theoretical analysis is required to establish under which circumstances (if any) limited dispersal of females may lead to sex ratio bias via LRE. A promising avenue for exploration will involve models of 'population elasticity', whereby the intensity of kin competition is reduced because extra resources are made available to local populations that are more cooperative (Taylor, 1992b; Gardner \& West, 2006). In the context of S. harmandi, these extra resources may include the larger hosts that can only be successfully parasitized by multiple foundresses acting as a cooperative unit.

Whereas the extent of female bias under LMC is expected to strongly depend upon the number of foundresses in the breeding group (Hamilton, 1967), the extent of female bias observed in $S$. harmandi does not appear to be strongly dependent upon foundress number (Tang et al., 2014). Formal theoretical exploration is needed to determine whether this is a 
general feature of LRE, or whether this relative invariance owes to a particular feature of $S$. harmandi's biology. Moreover, whereas a 'fertility insurance' effect, that curbs the evolution of extreme female-biased sex ratios in order to ensure the presence of at least some mating opportunities for daughters in the context of stochastic death or sterility of males, has been explored in the context of LMC (particularly in relation to protozoan parasites; West et al., 2002; Gardner et al., 2003), the impact of the threat of daughter virginity on a foundress's sex allocation decision remains to be explored in the context of LRE. The ability of unmated females to produce male offspring adds further complexity for sex ratio evolution (Godfray, 1990; West, 2009; Gardner, 2014).

In addition to improving our understanding of the sex allocation of these bethylid wasps, the proposed model development could also be used to understand the evolution of their quasisociality, both in terms of the evolution of reduced female dispersal and also in terms of the evolution of reduced aggressiveness and the emergence of coordinated cooperation between co-foundresses. In line with Gardner \& Ross's (2013) suggestion that a positive feedback between female-biased sex ratios and female-biased cooperation can promote eusociality, it would also be useful to assess the potential for such feedbacks to occur in this quasisocial context. In particular, whereas Gardner \& Ross's (2013) model required that some (unexplained) level of female cooperation be present at the outset, the biology of $S$. harmandi provides a ready explanation for cooperative breeding, i.e., a direct fitness benefit (Tang et al., 2014).

We conclude that considerations of the sex ratios of $S$. harmandi and its quasisocial congeners are currently constrained to be somewhat heuristic. This is essentially the same conclusion as reached by recent studies of sex ratios in Melittobia, another parasitoid genus in which similar degrees of sociality are observed (Innocent et al., 2010; Abe et al., 2014). This further understanding will likely develop best via a combination of field-based observations, experiments, and theoretical modelling.

\section{Acknowledgements}

We thank the late Dr Mark Jervis, who always showed an interest in our work on parasitoids and was always able to suggest connections to other research areas or study systems. He also engaged in several blues jam sessions with AK and ICWH, both in Cardiff and in Sutton Bonington, playing both guitar and bass guitar very adeptly. We greatly miss these academic and non-academic interactions with him. We further thank Ling Meng, Fuyan Xu, Xie Chunxia, Zheng Huayin, Xu Ming, Liu Conghui, Wu Shaolong, and Richard Wilkinson for 
1 their help. This study was supported by Natural Science Foundation of China (31570389).

2 AK was supported by a Marie Curie Fellowship (FP7-PEOPLE-2010-IEF 273431). AG was

3 funded by a Natural Environment Research Council (UK) Independent Research Fellowship

4 (NE/K009524/1).

5

6 References

7 Abe J \& KamimuraY (2012) Do female parasitoid wasps recognise and adjust sex ratios to build cooperative relationships? Journal of Evolutionary Biology 25: 1427-1437.

Abe J \& Kamimura Y (2015) Sperm economy between female mating frequency and male ejaculate allocation. American Naturalist 185: 406-416.

Abe J, Kamimura Y \& West SA (2014) Inexplicable female-biased sex ratios in Melittobia wasps. Evolution 68: 2709-2717.

Bourke AFG (2011) Principles of Social Evolution. Oxford University Press, Oxford, UK.

Bourke AFG \& Franks NR (1995) Social Evolution in Ants. Princeton University Press, Princeton, NJ, USA.

Bridwell JC (1920) Some notes on Hawaiian and other Bethylidae (Hymenoptera) with the description of a new genus and species, 2nd paper. Proceedings of the Hawaiian Entomological Society 4: 291-314.

Bulmer MG (1986) Sex ratio theory in geographically structured populations. Heredity 56: 69-73.

Casale A (1991) Some notes on the parental and parasocial behaviour of Sclerodermus domesticus Latreille (Hymenoptera: Bethylidae). Ethology Ecology \& Evolution 1: 3538.

Charnov EL (1982) The Theory of Sex Allocation. Princeton University Press, Princeton, NJ, USA.

Chen J \& Cheng H (2000) Advances in applied research on Sclerodermus spp. Chinese Journal of Biological Control 16: 166-170.

Frank SA (1986) The genetic value of sons and daughters. Heredity 56: 351-354.

Gardner A (2014) Dynamics of sex ratio and female unmatedness under haplodiploidy. Ecology and Evolution 4: 1623-1628.

Gardner A, Arce A \& Alpedrinha J (2009) Budding dispersal and the sex ratio. Journal of Evolutionary Biology 22: 1036-1045.

Gardner A, Reece SE \& West SA (2003) Even more extreme fertility insurance and the sex ratios of protozoan blood parasites. Journal of Theoretical Biology 223: 515-521. 
1 Gardner A \& Ross L (2013) Haplodiploidy, sex-ratio adjustment, and eusociality. American Naturalist 181: E60-E67.

Gardner A \& West SA (2006) Demography, altruism, and the benefits of budding. Journal of Evolutionary Biology 19: 1707-1716.

Godfray HCJ (1990) The causes and consequences of constrained sex allocation in haplodiploid animals. Journal of Evolutionary Biology 3: 3-17.

Godfray HCJ (1994) Parasitoids: Behavioral and Evolutionary Ecology. Princeton University Press, Princeton, NJ, USA.

Godfray HCJ \& Cook JM (1997) Mating systems of parasitoid wasps. The Evolution of Mating Systems in Insects and Arachnids (ed. by JC Choe \& BJ Crespi), pp. 211-225. Cambridge University Press, Cambridge, UK.

Gordh G, Woolley JB \& Medeved RA (1983) Biological studies on Goniozus legneri Gordh (Hymenoptera: Bethylidae), primary external parasite of the navel orangeworm Amyelois transitella and pink bollworm Pectinophora gossypiella (Lepidoptera: Pyralidae, Gelechiidae). Contributions of the American Entomological Institute 20: 433-468.

Green RF, Gordh G \& Hawkins BA (1982) Precise sex ratios in highly inbred parasitic wasps. American Naturalist 120: 653-665

Griffiths NT \& Godfray HCJ (1988) Local mate competition, sex ratio and clutch size in bethylid wasps. Behavioral Ecology and Sociobiology 22: 211-217.

Hamilton WD (1964) The genetical evolution of social behaviour, I \& II. Journal of Theoretical Biology 7: 1-52

Hamilton WD (1967) Extraordinary sex ratios. Science 156: 477-488.

Hamilton WD (1979) Wingless and fighting males in fig wasps and other insects. Reproductive Competition, Mate Choice and Sexual Selection in Insects (ed. by MS Blum \& NA Blum), pp. 167-220. Academic Press, London, UK.

Hardy ICW (1992) Non-binomial sex allocation and brood sex ratio variances in the parasitoid Hymenoptera. Oikos 65: 143-158

Hardy ICW (1994) Sex ratio and mating structure in the parasitoid Hymenoptera. Oikos 69: $3-20$.

Hardy ICW (2002) Sex Ratios: Concepts and Research Methods. Cambridge University Press, Cambridge, UK.

Hardy ICW \& Cook JM (1995) Brood sex ratio variance, developmental mortality and virginity in a gregarious parasitoid wasp. Oecologia 103: 162-169.

Hardy ICW \& Mayhew PJ (1998) Sex ratio, sexual dimorphism and mating structure in 
bethylid wasps. Behavioral Ecology and Sociobiology 42:383-395

Hardy ICW, Dijkstra LJ, Gillis JEM \& Luft PA (1998) Patterns of sex ratio, virginity and developmental mortality in gregarious parasitoids. Biological Journal of the Linnean Society 64: 239-270.

Hardy ICW, Goubault M \& Batchelor TP (2013) Hymenopteran contests and agonistic behaviour. Animal Contests (ed. by ICW Hardy \& M Briffa), pp. 147-177. Cambridge University Press, Cambridge, UK.

Hardy ICW, Ode PJ \& Siva-Jothy M (2005) Mating systems. Insects as Natural Enemies: A Practical Perspective, 2nd edn (ed. by MA Jervis), pp. 261-298. Springer, Dordrecht, The Netherlands.

Hardy ICW, Stokkebo S, Bønløkke-Pedersen J \& Sejr MK (2000) Insemination capacity and dispersal in relation to sex allocation decisions in Goniozus legneri (Hymenoptera: Bethylidae): why are there more males in larger broods? Ethology 106: 1021-1032.

Harradine SL, Gardner MG \& Schwarz MP (2012) Kinship in a social bee mediates ovarian differentiation and has implications for reproductive skew theories. Animal Behaviour 84: 611-618.

He J (2004) Hymenopteran Insect Fauna of Zhejiang. Science Press, Beijing, China. Heimpel GE (1994) Virginity and the cost of insurance in highly inbred Hymenoptera. Ecological Entomology 19: 299-302.

Hu Z, Zhao X, Li Y, Liu X \& Zhang Q (2012) Maternal care in the parasitoid Sclerodermus harmandi (Hymenoptera: Bethylidae). PLoS ONE 7(12): e51246.

Innocent TM, Abe J, West SA \& Reece SE (2010) Competition between relatives and the evolution of dispersal in a parasitoid wasp. Journal of Evolutionary Biology 23: 13741385.

Kapranas A, Hardy ICW, Luck RF \& Morse JG (2011) Parasitoid developmental mortality in the field: patterns, causes and consequences for sex ratio and virginity. Journal of Animal Ecology 80: 192-203.

Kapranas A, Wajnberg E \& Luck RF (2009) Sequences of sex allocation and mortality in clutches of Metaphycus parasitoids of soft scale insects and the prevalence of all-female broods. Ecological Entomology 34: 652-662.

Khidr SK, Hardy ICW, Zaviezo T \& Mayes S (2014) Development of microsatellite markers and detection of genetic variation between Goniozus wasp populations. Journal of Insect Science 14: 43.

Khidr SK, Mayes S \& Hardy ICW (2013) Primary and secondary sex ratios in a gregarious 
parasitoid with local mate competition. Behavioural Ecology 24: 435-443.

Krackow S, Meelis E \& Hardy ICW (2002) Analysis of sex ratio variances and sequences of sex allocation. Sex Ratios: Concepts and Research Methods (ed. by ICW Hardy), pp. 112-131. Cambridge University Press, Cambridge, UK.

Kühne H \& Becker G (1974) Zur Biologie und Ökologie von Scleroderma domesticum Latreille (Bethylidae, Hymenoptera) einem Parasiten Holzzerstörender Insektenlarven. Zeitschrift für Angewandte Entomologie 76: 270-303.

Li L \& Sun J (2011) Host suitability of a gregarious parasitoid on beetle hosts: Flexibility between fitness of adult and offspring. PLoS ONE 6(4): e18563.

Liu Z, Xu B, Li L \& Sun J (2011) Host-size mediated trade-off in a parasitoid Sclerodermus harmandi. PLoS ONE 6(8): e23260.

Mamaev BM (1979) Entomophages of tree-trunk pests-hymenopterans of the genus Scleroderma Latr. (Hymenoptera, Bethylidae). Insects destroying wood and their entomophages. Nasekomye razrushiteli drevesiny i ikh entomofagi 44-64. (In Russian)

Martins RP, Antonini Y, da Silveria FA \& West SA (1999) Seasonal variation in the sex allocation of a neotropical solitary bee. Behavioural Ecology 4: 401-408.

Matthews RW, Gonzáles JM, Matthews JR \& Deyrup LD (2009) Biology of the parasitoid Melittobia (Hymenoptera: Eulophidae). Annual Review of Entomology 54: 251-266.

Nagelkerke CJ (1996) Discrete clutch sizes, local mate competition, and the evolution of precise sex allocation. Theoretical Population Biology 49: 314-343.

Nagelkerke CJ \& Hardy ICW (1994) The influence of developmental mortality on optimal sex allocation under local mate competition. Behavioural Ecology 5: 401-411.

Nagelkerke CJ \& Sabelis MW (1998) Precise control of sex allocation in pseudoarrhenotokous phytoseiid mites. Journal of Evolutionary Biology 11: 649-684.

Orzack SH (2002) Using sex ratios: the past and the future. Sex Ratios: Concepts and Research Methods (ed. by ICW Hardy), pp. 383-398. Cambridge University Press, Cambridge, UK.

Rodrigues A \& Gardner A (2015) Simultaneous failure of two sex-allocation invariants: implications for sex-ratio variation within and between populations. Proceedings of the Royal Society B 282: 20150570..

Schwarz MP (1988) Local resource enhancement and sex ratios in a primitively social bee. Nature 331: 346-348.

Shuker DM, Pen I, Duncan AB, Reece SE \& West SA (2005) Sex ratios under asymmetrical local mate competition: theory and a test with parasitoid wasps. American Naturalist 
166: 301-316.

Shuker DM, Reece SE, Taylor JAL \& West SA (2004) Wasp sex ratios when females on a patch are related. Animal Behaviour 68:331-336.

Tang X, Meng L, Kapranas A, Xu F, Hardy ICW \& Li B (2014) Mutually beneficial host exploitation and ultra-biased sex ratios in quasisocial parasitoids. Nature Communications 5: 1-7.

Taylor PD (1981) Intra-sex and inter-sex sibling interactions as sex ratio determinants. Nature 291:64-66.

Taylor PD (1988) Inclusive fitness models with two sexes. Theoretical Population Biology 34: $145-168$.

Taylor PD (1992a) Altruism in viscous populations: an inclusive fitness approach. Evolutionary Ecology 6: 352-356.

Taylor PD (1992b) Inclusive fitness in a heterogeneous environment. Proceedings of the Royal Society of London B 249: 299-302.

Taylor PD \& Crespi BJ (1994) Evolutionary stable strategy sex ratios when correlates of relatedness can be assessed. American Naturalist 143: 297-316.

Werren JH (1983) Sex ratio evolution under local mate competition. Evolution 37: 116-124.

West SA \& Herre EA (1998) Stabilizing selection and variance in fig wasp sex ratios. Evolution 52: 475-485.

West SA (2009) Sex Allocation. Princeton University Press, Princeton, NJ, USA.

West SA, Herre EA, Compton SG, Godfray HCJ \& Cook JM (1997) A comparative study of virginity in fig wasps. Animal Behaviour 54: 437-450.

West SA, Smith TG, Nee S \& Read AF (2002) Fertility insurance and the sex ratios of malaria and related hemospororin blood parasites. Journal of Parasitology 88: 258-263.

Wheeler WW (1928) The Social Insects: Their Origin and Evolution. Harcourt, Brace \& Co., New York, NY, USA.

Wilson K \& Hardy ICW (2002) Statistical analysis of sex ratios: an introduction. Sex Ratios: Concepts and Research Methods (ed. by ICW Hardy), pp. 48-92. Cambridge University Press, Cambridge, UK.

Wilson EO (1971) The Insect Societies. Harvard University Press, Cambridge, MA, USA.

Wu S-L, Xu F-Y, Li B-P \& Ling M (2013) Initiation and rhythm of larva-translocation behaviour during material care in an ectoparasitoid Sclerodermus guani (Hymenoptera: Bethylidae). Acta Entomologica Sinica 56: 392-397.

Xu K, Xu F, Wang M, Zhao J, Jiang Q et al. (2002) The techniques of Sclerodermus guani 

26: $48-52$.

3 Yang Z-Q, Wang X-Y \& Zhang YN (2014) Recent advances in biological control of important native and invasive forest pests in China. Biological Control 68: 117-218.

Zhang Z-X \& Tian S-Z (1985) A preliminary report of biology and application of a bethylid wasp attacking longhorned beetles. Entomological Knowledge 17: 71-73.

7

8

\section{$9 \quad$ Figure captions}

Figure 1 Relationships between sex ratio (proportion of adult offspring that were males) and brood size at emergence, for broods founded by 1 to8 adult female Sclerodermus harmandi. Fitted logistic regression lines are provided for each foundresses group. Note that for visual clarity the fitted logistic regression line for 2-foundresses broods is slightly displaced below the 4-foundresses regression line.

Figure 2 The relationship between sex ratio at adult emergence (proportion males) and the proportion of developmental mortality in offspring groups of Sclerodermus harmandi. The fitted line is from logistic regression.

Figure 3 The influence of offspring group size at adult emergence on virginity (proportion of broods that were all-female) in Sclerodermus harmandi. The fitted line is from logistic regression.

Figure 4 The influence of foundress number and mortality on virginity (proportion of broods that were all-female) in Sclerodermus harmandi. The fitted lines are based on logistic analysis of covariance, treating foundress group size as a discrete factor. 


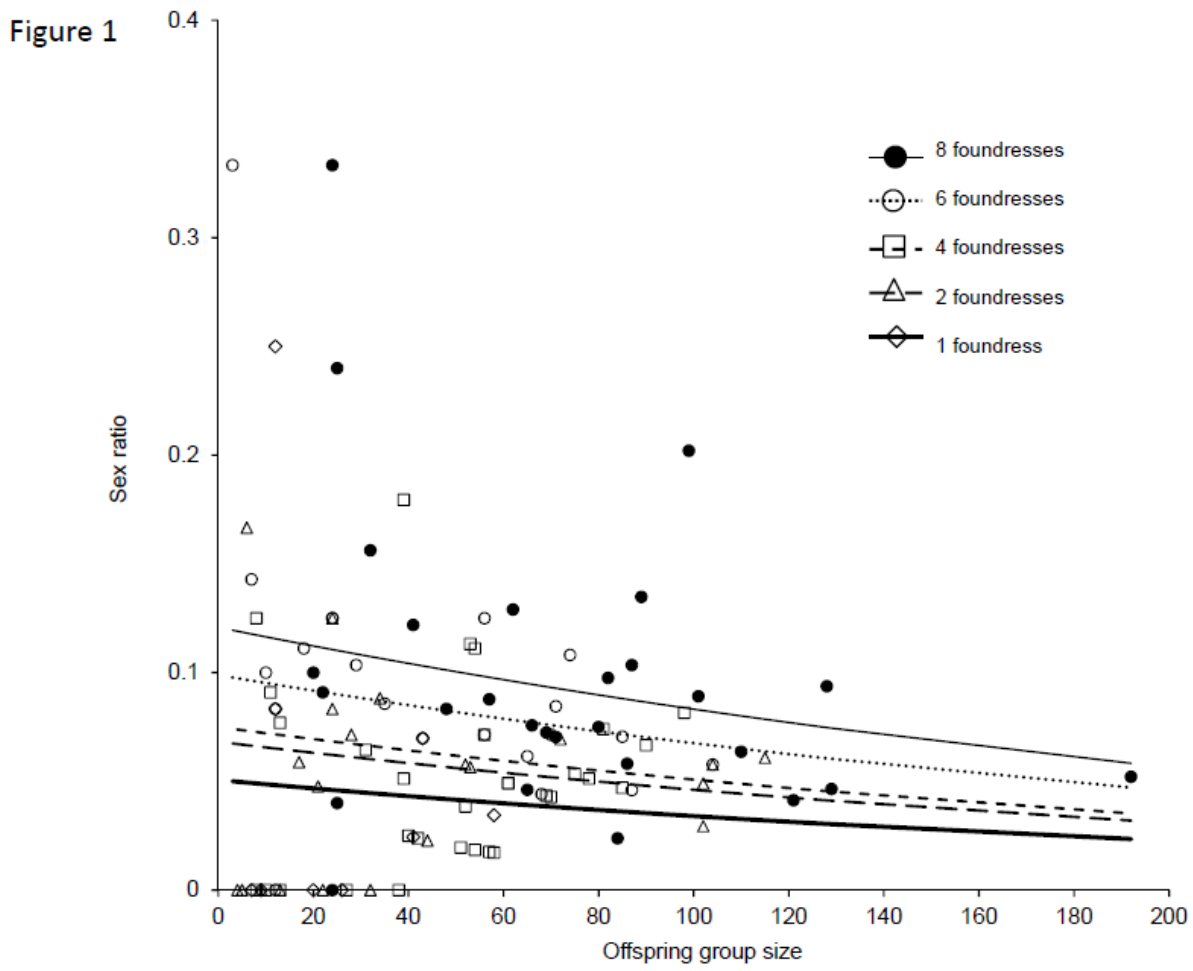

Figure 2

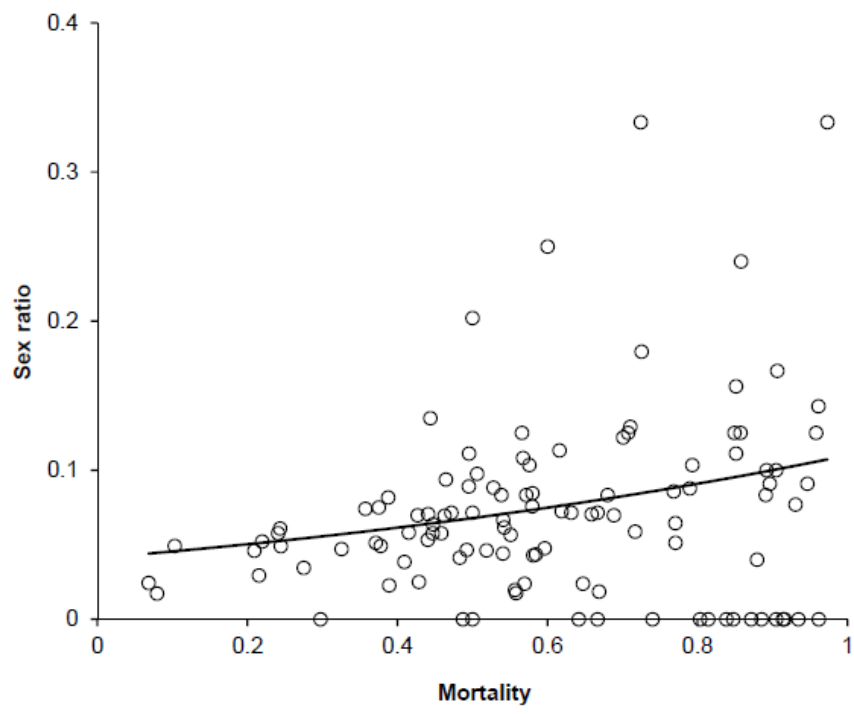


Figure 3

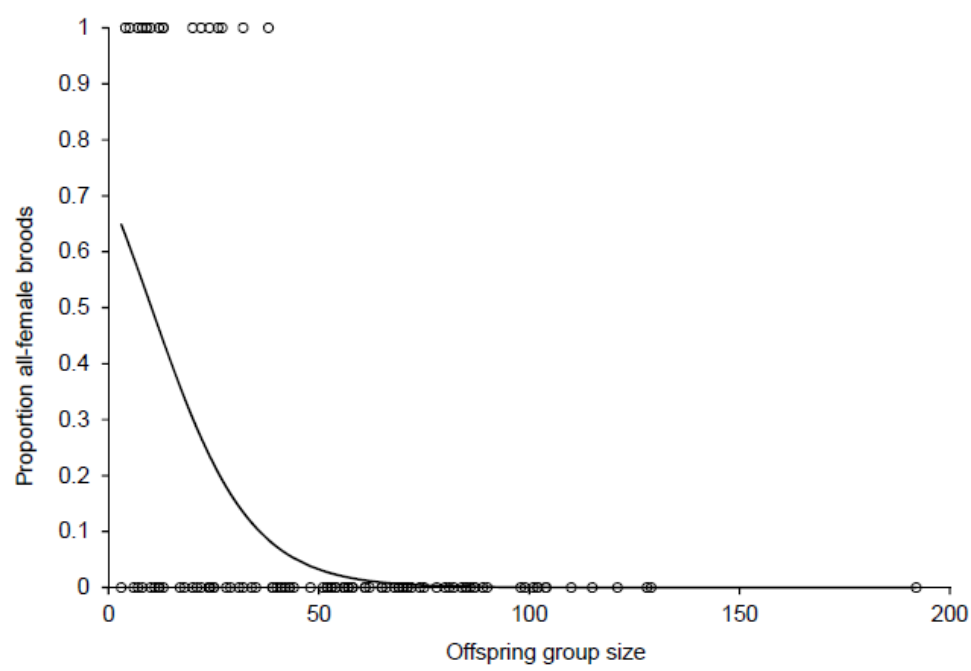

Figure 4

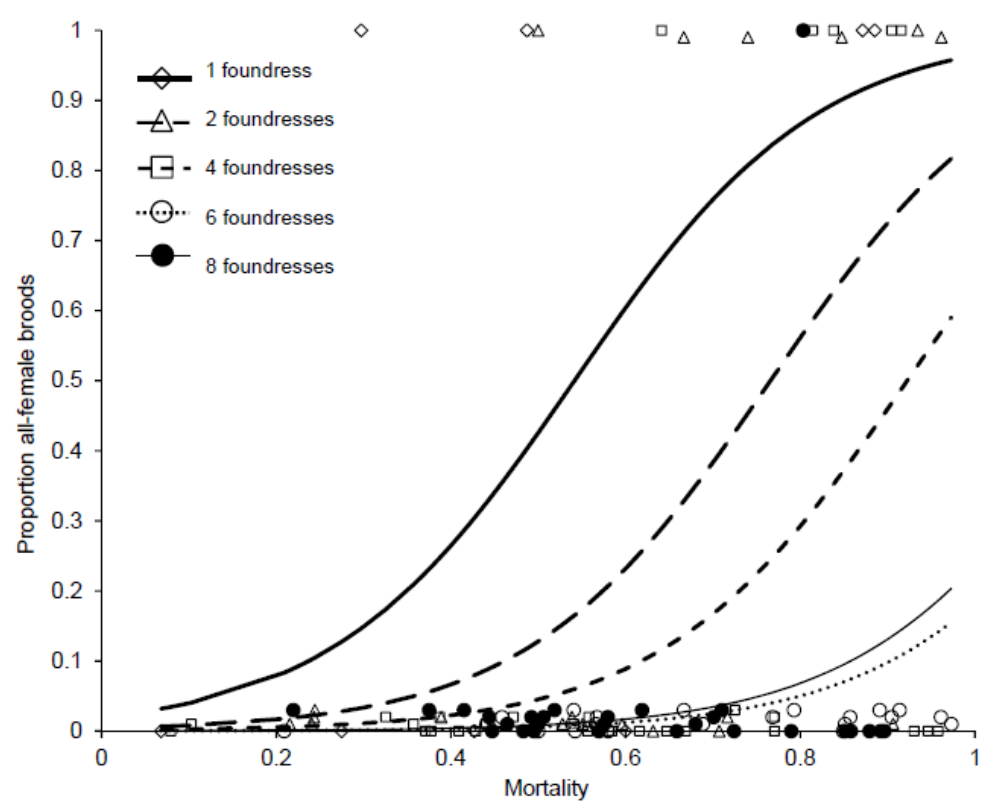

